\title{
Comparison of rechargeable versus battery- operated insulin pumps: temperature fluctuations
}

This article was published in the following Dove Press journal:

Medical Devices: Evidence and Research

14 October 2016

Number of times this article has been viewed

\author{
Paul Vereshchetin \\ Thomas W McCann Jr \\ Navdeep Ojha \\ Ramakrishna Venugopalan \\ Brian L Levy \\ Johnson \& Johnson Diabetes Care \\ Companies, Chesterbrook, PA, USA
}

Correspondence: Paul Vereshchetin Johnson \& Johnson Diabetes Care Companies, 965 Chesterbrook

Boulevard, Chesterbrook,

PA 19087, USA

Tel +l 4843286229

Email pvereshc@its.jnj.com

\begin{abstract}
The role of continuous subcutaneous insulin infusion (insulin pumps) has become increasingly important in diabetes management, and many different types of these systems are currently available. This exploratory study focused on the reported heating issues that lithium-ion battery-powered pumps may have during charging compared with battery-operated pumps. It was found that pump temperature increased by $6.4^{\circ} \mathrm{C}$ during a long charging cycle of a lithiumion battery-operated pump under ambient temperatures. In an environmental-chamber kept at $35^{\circ} \mathrm{C}$, the pump temperature increased by $4.4^{\circ} \mathrm{C}$, which indicates that the pump temperature was above that of the recommended safety limit for insulin storage of $37^{\circ} \mathrm{C}$. When designing new pumps, and when using currently available rechargeable pumps in warmer climates, the implications of these temperature increases should be taken into consideration. Future studies should also further examine insulin quality after charging.
\end{abstract}

Keywords: insulin pumps, diabetes mellitus, safety, heating

\section{Introduction}

Continuous subcutaneous insulin infusion (insulin pump) therapy is an effective method of managing glycemic control in people with diabetes mellitus who require insulin. As such, accurate and reliable insulin delivery is a top priority when using an insulin pump. ${ }^{1}$ As the use of insulin pumps has increased, many different rechargeable and battery-operated systems have been created.

Rechargeable lithium-ion batteries are becoming popular power sources for portable electronic devices, including insulin pumps. ${ }^{2}$ The electrolytes contained within the battery have excellent conductivity and life-cycle performance. However, there are risks associated with the use of lithium-ion batteries, such as leakage and fire hazards. Furthermore, excessive heat exposure may cause the separator (a membrane inside the battery) to shrink or melt, causing a short circuit between the two electrodes., ${ }^{2,3}$ Prolonged exposure to high temperatures, such as those that may occur if a rechargeable battery is repeatedly overcharged or if the pump is exposed to direct sunlight, leads to increased heat production within the battery.

Insulin manufacturers specify that insulin temperatures should not exceed $37^{\circ} \mathrm{C} ;{ }^{4,5}$ temperatures above this cutoff carry the risk of insulin degradation, with the associated consequences of prolonged hyperglycemia. ${ }^{6,7}$ Previous studies have shown that exposure to temperatures higher than $37^{\circ} \mathrm{C}$ may increase the risk of insulin fibrillation, a form of protein misfolding that leads to the development of precipitates in insulin solutions. ${ }^{8}$ Therefore, temperature fluctuations in rechargeable 
insulin pumps may have significant implications for the stability of the insulin in the pump. However, temperature fluctuations in nonrechargeable battery-operated pumps have not yet been examined compared with those using rechargeable batteries.

Changes in insulin temperature may potentially affect insulin action, and thus have the potential to compromise glycemic control and/or safety. Therefore, the goal of this study was to evaluate temperature fluctuations during the charging period of rechargeable insulin pumps, and compare them with temperature fluctuations in battery-operated insulin pumps, in both ambient temperatures (eg, usual home/office temperature in the US) and in a high-temperature environment (eg, outdoors on a summer day in the US).

\section{Materials and methods Materials and equipment}

The materials and equipment required for this study included an extruded polystyrene rigid-foam insulation board $(61 \times 45.7 \times 2.5 \mathrm{~cm}$, Foamular $\AA$; Owens Corning, Toledo, $\mathrm{OH}, \mathrm{USA}$ ) to prevent stray heat conduction between the experimental pumps. The design also included a TiS40 infrared (IR) camera and two 54 II B thermometers for measuring air and insulin-pump temperatures (Fluke Corporation, Everett, WA, USA). The 54 II B thermometers, together with Chromega-Alomega thermocouples (SA1-K-72-SC, gauge 30 [0.025 cm], length $182.9 \mathrm{~cm}$; Omega Engineering Inc, Stamford, CT, USA) were used to monitor insulin-pump and ambient temperatures. A temperature-controlled environment was simulated in a Hotpack environmental-chamber (417522; SP Industries, Warminster, PA, USA). All devices were calibrated and certified at time of use.

Six t:slim pumps (Tandem Diabetes Care Inc, San Diego, CA, USA) were used as insulin pumps with rechargeable batteries. Six Vibe pumps (Animas Diabetes Care LLC, West Chester, PA, USA) were used as insulin pumps with regular batteries. High-purity water with food dye (McCormick, Sparks, MD, USA) was used in lieu of insulin to fill cartridges and prime pumps.

\section{Experimental design: pump testing}

The study set up was constructed and conducted on the extruded polystyrene rigid-foam insulation board in ambient temperature (Figure 1A) and in a temperature-controlled environmental-chamber (Figure 1B). Two thermometers (54 II B) were used to measure pump and air temperatures. One thermometer was used to measure pump temperatures and required two thermocouples: one attached to the rear of the rechargeable pump located in the center of the set up (Figure 1C), and one attached to the rear of the batteryoperated pump. Both thermocouples were attached at the location of the insulin cartridge. A separate thermometer, with one thermocouple, provided reference air-temperature measurements in both settings. For both ambient-air and environmental-chamber temperature measurements, the IR camera was set up on a tripod, targeting the rechargeable pump located in the center of the set up, and capturing all 12 pumps in the IR camera frame.

During the ambient-temperature study, IR pictures were taken every 60 seconds, and insulin-pump temperature and air temperature were logged every 60 seconds over the course of a 3-hour period. Measurements were started just prior to the power strip being plugged in. IR imaging was used to register and demonstrate temperature changes of all 12 pumps, but thermocouple measurements were conducted on only one sample of each type, to quantify the extent of heating. During the elevated-temperature study, the environmental-chamber was heated to $35^{\circ} \mathrm{C}$, and the equipment was set up as depicted in Figure 1B. The chamber's design allows the pulling of a power cable through to the outside, which can then be plugged in without opening the chamber. The environmental-chamber door was securely closed, and 2 hours were allowed before the start of the study to let the temperature return to $35^{\circ} \mathrm{C}$. Once the proper temperature was reached, the power strip was plugged in, initiating the charging period for the rechargeable pumps. IR pictures were taken every 60 seconds, and insulin pump temperature and air temperature were logged every 60 seconds over the course of a 3 -hour period.

For both experiments, rechargeable pumps were either low on battery or drained when charging initiated, while battery-operated pumps were equipped with new batteries. Pumps stayed plugged in for 3 hours. The rechargeable pumps were fully charged after approximately 70 minutes, as judged at the end of the temperature climb.

\section{Results}

For the rechargeable pumps, the sensor readouts indicated temperature increases in both the ambient- and elevatedtemperature settings. An increase of $6.4^{\circ} \mathrm{C}$ from the initial temperature was measured in the ambient-temperature setting (Figure 2). The sensor readouts also indicated an increase of $4.4^{\circ} \mathrm{C}$ from the initial temperature in the environmental-chamber setting, which was kept at a constant $35^{\circ} \mathrm{C}$ (Figure 3), with a maximum measured temperature of $40.4^{\circ} \mathrm{C}$. 
A

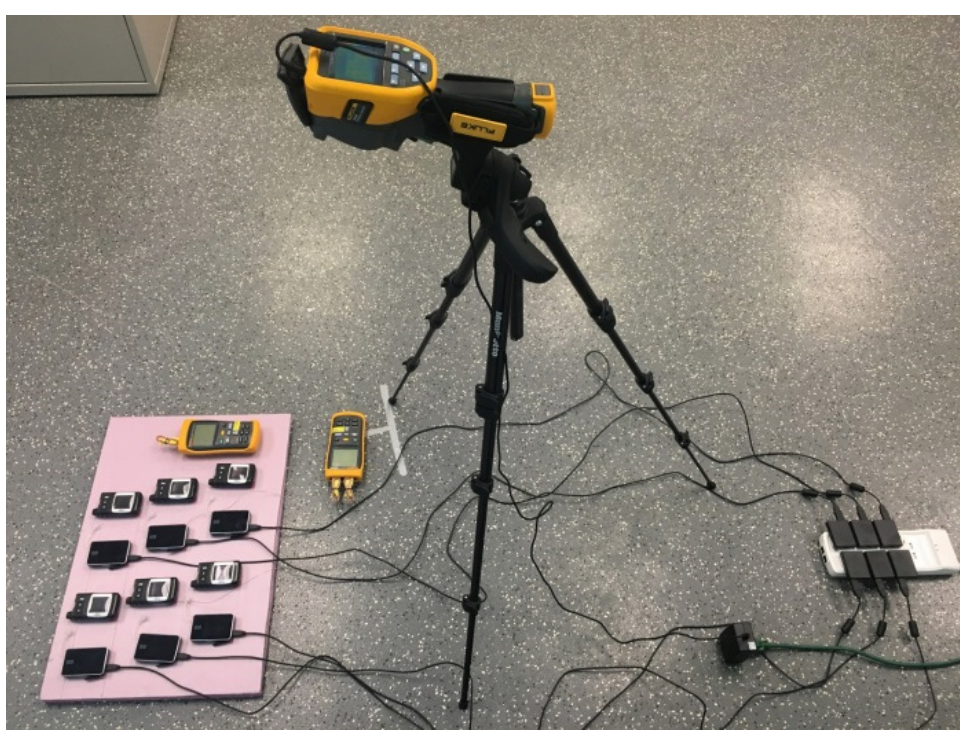

B

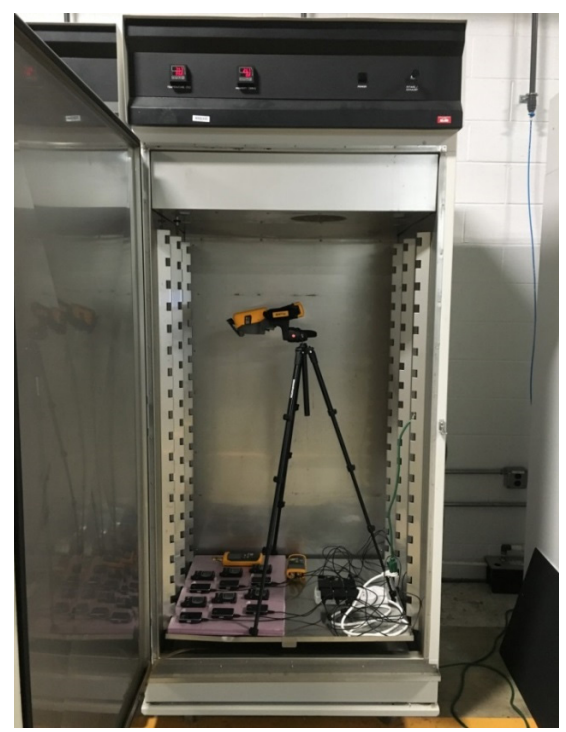

C

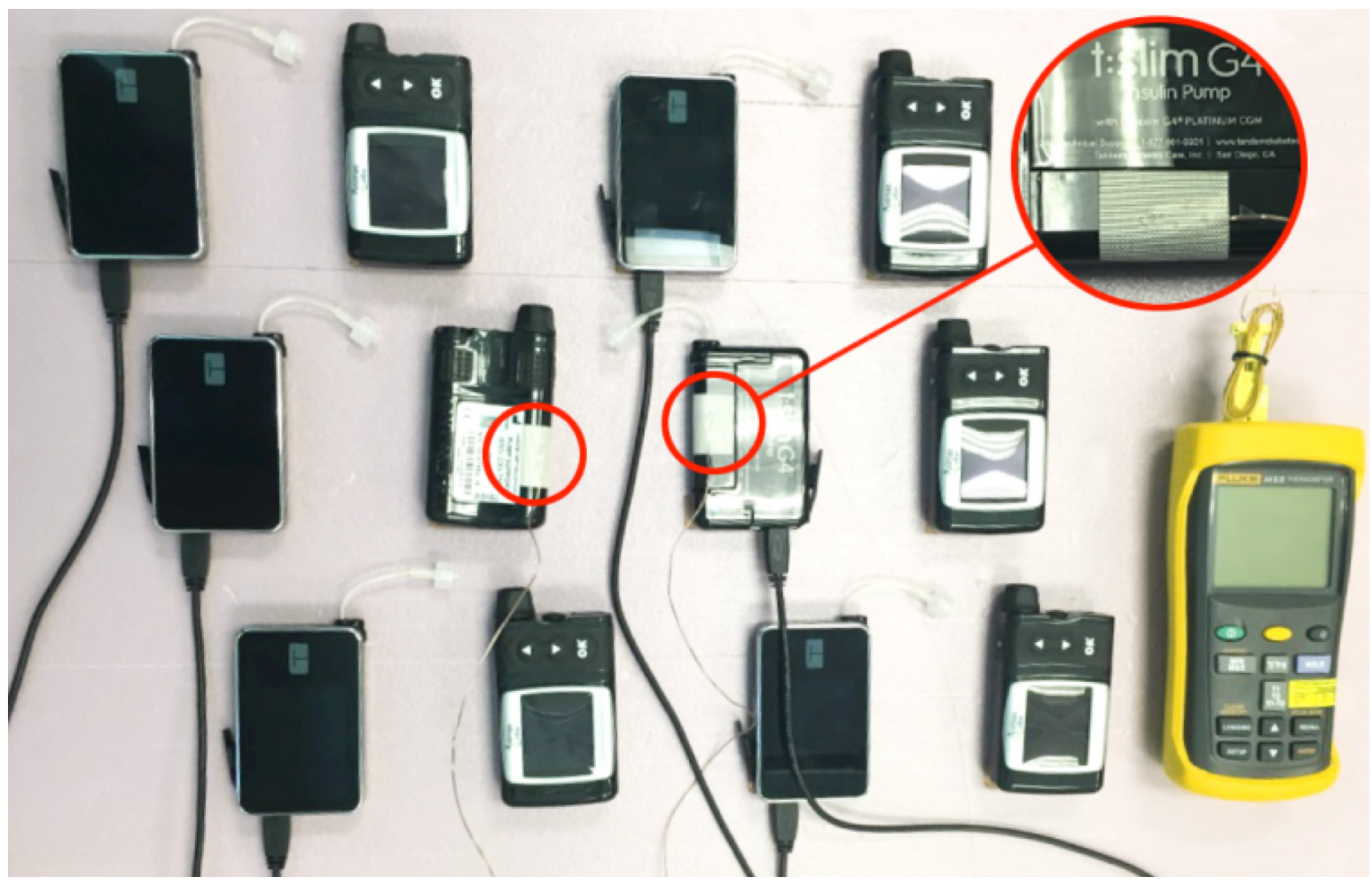

Figure I Ambient (A) and environmental-chamber (B) temperature-measurement set up and sensor placement (C).

Note: Images show infrared camera on tripod, foam board containing six battery-operated pumps, six rechargeable pumps, and two sensors.

The IR camera also revealed an apparent increase from the initial temperature in the environmental-chamber setting (Figure 4). The IR camera showed a $2.7^{\circ} \mathrm{C}$-higher starting temperature compared with the actual chamber temperature. No significant temperature differences were found between the battery-operated pumps in either the environmentalchamber $\left(35.9^{\circ} \mathrm{C}\right)$ or the ambient setting $\left(22.6^{\circ} \mathrm{C}\right)$.

\section{Discussion}

In this study, temperatures measured during a full charging period of the rechargeable lithium-ion battery pump (70 minutes) were shown to increase substantially over time in both the ambient-temperature setting and in the temperaturecontrolled environmental-chamber. The results further showed that the temperatures of the rechargeable insulin 


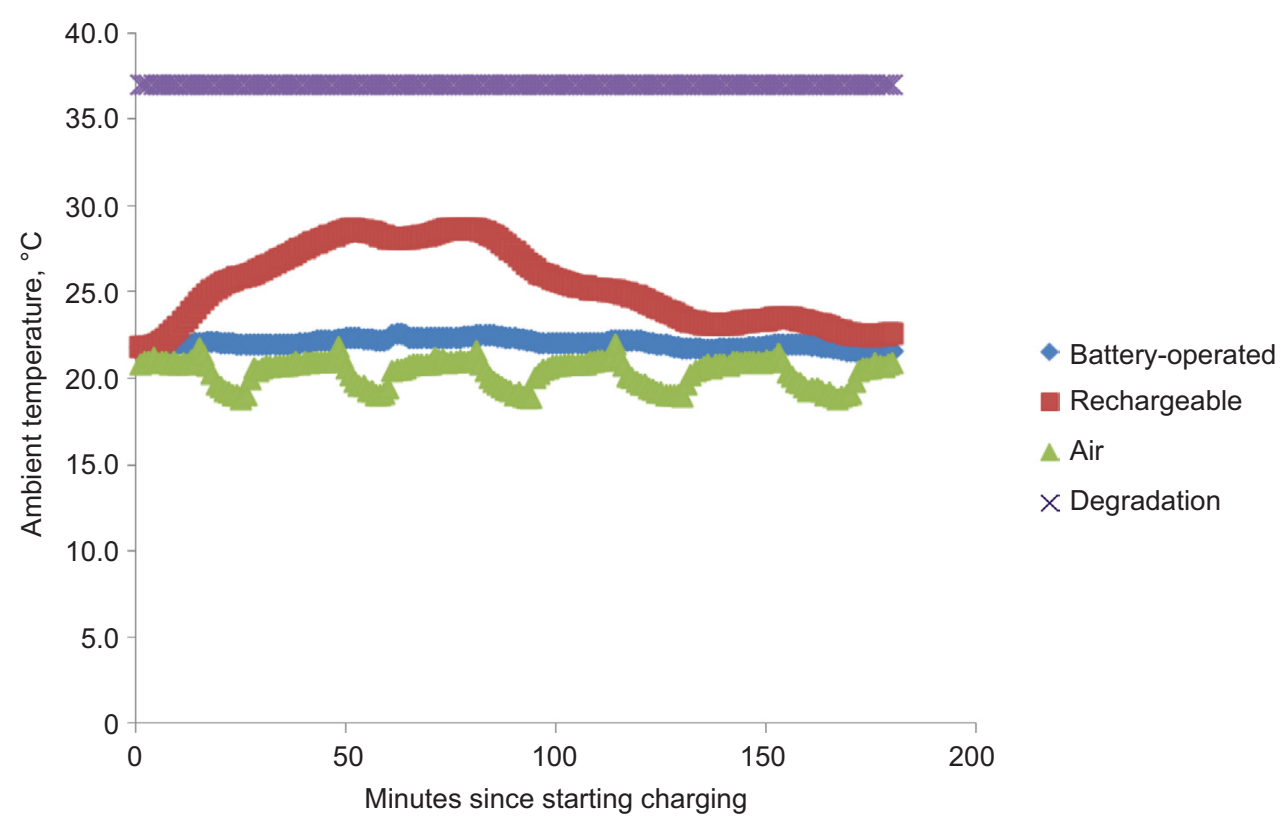

Figure 2 Ambient-temperature results.

Notes: Battery and rechargeable battery pump temperatures, insulin degradation temperature, and ambient air temperatures shown, measured over 180 minutes.

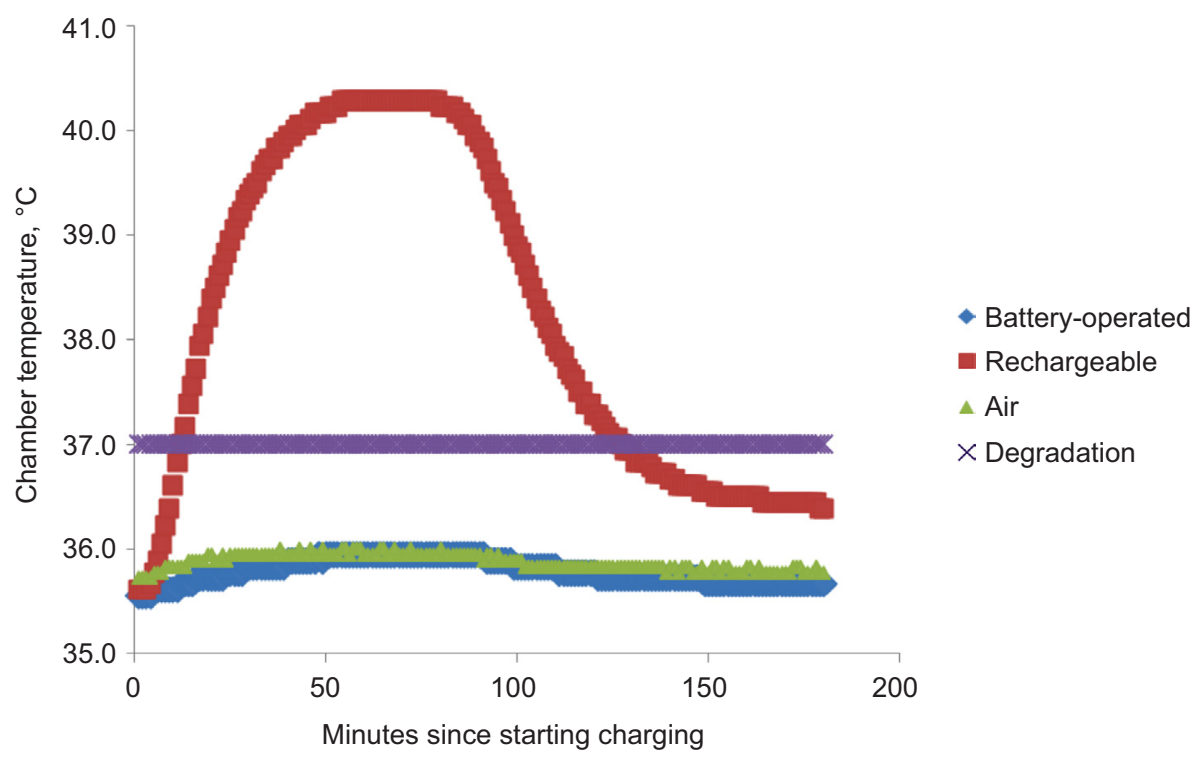

Figure 3 Enviromental-chamber temperature results.

Notes: Battery and rechargeable battery pump temperatures, insulin degradation temperature, and chamber temperatures are shown, measured over 180 minutes in a controlled $\left(35^{\circ} \mathrm{C}\right)$ environment.

pumps often exceeded $37^{\circ} \mathrm{C}$ in an environment with an elevated temperature of $35^{\circ} \mathrm{C}$ during a full charging period. In contrast, the battery-operated pumps showed little or no temperature fluctuation in either environment. Manufacturers of rechargeable insulin pumps suggest charging the battery for no longer than 10-15 minutes per day, possibly to avoid overcharging and the associated consequences described here. However, manufacturers do not actually prohibit charging longer, ${ }^{9}$ and thus a full-charge cycle as tested here is not an unlikely scenario.
Insulin-analog manufacturer specifications indicate that their product should not be exposed to temperatures over $37^{\circ} \mathrm{C} .{ }^{4,5}$ The labeling information containing instructions for diabetes patients using insulin pumps states that the temperature of the insulin in the pump cartridge may exceed ambient temperature when the pump housing, cover, tubing, or sport case is exposed to sunlight or radiant heat. ${ }^{4}$ During exploratory experiments in which temperature sensors were placed inside the pump cartridge, additional heating beyond what was observed in the current study was noted (data not 


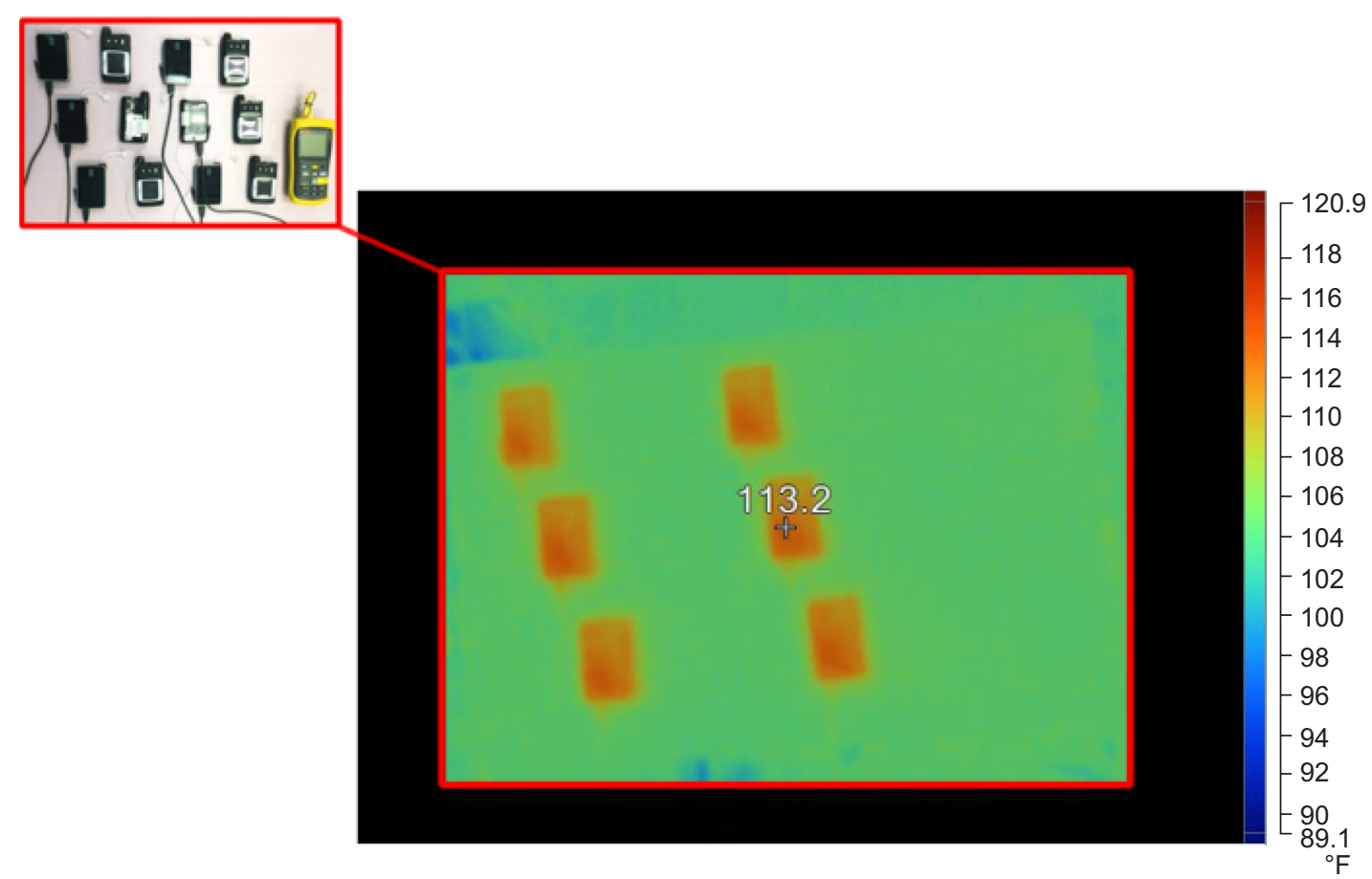

Figure 4 Infrared image of temperature increases in rechargeable pumps, with the layout of the devices in the top-left corner.

Note: Measurements were performed in the environmental-chamber which was maintained at a constant temperature $\left(35^{\circ} \mathrm{C}, 95^{\circ} \mathrm{F}\right)$.

shown; due to the invasive nature of these exploratory experiments, which required manipulation of the insulin pumps, it was decided that these experiments were not representative of appropriate pump use). In the study described here, it was shown that during charging, insulin pumps with rechargeable lithium-ion batteries were subjected to temperature increases that may exceed the recommended temperatures for insulin storage and handling, especially in warm environments. These temperature variations may result in unexplained glycemic variability in the patient, as higher temperatures may result in compromised insulin quality.

\section{Conclusion}

By measurements, we have shown that lithium-ion rechargeable batteries, such as those currently used to power insulin pumps, showed substantial temperature increases during a full charging period in both ambient conditions and warm environments compared with battery-operated pumps. When charging in warm environments, rechargeable pump temperatures may exceed the temperature recommended for insulin storage and handling, potentially affecting the reliability of insulin action. When using lithium-ion rechargeable batteries in the design of new pumps, the implications of these temperature increases should be taken into consideration, as well as the effect heating may have on insulin quality, especially in warmer climates, as mentioned earlier, as the effects were largest in the environmental-chamber.
The effect on insulin will have to be further examined in future studies.

\section{Acknowledgments}

This study was sponsored by Animas Corporation. The authors received editorial/writing support from Excerpta Medica in the preparation of this manuscript.

\section{Disclosure}

This study was sponsored by Animas Corporation. The authors report no other conflicts of interest in this work.

\section{References}

1. Peyrot M, Rubin RR, Chen X, Frias JP. Associations between improved glucose control and patient-reported outcomes after initiation of insulin pump therapy in patients with type 2 diabetes mellitus. Diabetes Technol Ther. 2011;13(4):471-476.

2. Shin WK, Cho J, Kannan AG, Lee YS, Kim DW. Cross-linked composite gel polymer electrolyte using mesoporous methacrylate-functionalized $\mathrm{SiO}_{2}$ nanoparticles for lithium-ion polymer batteries. Sci Rep. 2012;6:26332.

3. Wen JW, Yu Y, Chen $\mathrm{CH}$. A review on lithium-ion batteries safety issues: existing problems and possible solutions. Mater Express. 2012;2(3):197-212.

4. Humalog [prescribing information]. Available from: http://pi.lilly.com/ us/humalog-pen-pi.pdf. Accessed September 20, 2016.

5. NovoLog [prescribing information]. Available from: http://www.novo-pi. com/novolog.pdf. Accessed September 20, 2016.

6. Kerr D, Wizemann E, Senstius J, Zacho M, Ampudia-Blasco FJ. Stability and performance of rapid-acting insulin analogs used for continuous subcutaneous insulin infusion: a systematic review. J Diabetes Sci Technol. 2013;7(6):1595-1606.

7. Woods RJ, Alarcón J, McVey E, Pettis RJ. Intrinsic fibrillation of fastacting insulin analogs. J Diabetes Sci Technol. 2012;6(2):265-276. 
8. Phillips NB, Whittaker J, Ismail-Beigi F, Weiss MA. Insulin fibrillation and protein design: topological resistance of single-chain analogs to thermal degradation with application to a pump reservoir. $J$ Diabetes Sci Technol. 2012;6(2):277-288.
9. t:slim [user guide]. Available from: https://www.tandemdiabetes.com/ docs/default-source/product-documents/tslim-insulin-pump/updated-tslim-user-guide.pdf. Accessed September 20, 2016.

\section{Publish your work in this journal}

Medical Devices: Evidence and Research is an international, peerreviewed, open access journal that focuses on the evidence, technology, research, and expert opinion supporting the use and application of medical devices in the diagnosis, monitoring, treatment and management of clinical conditions and physiological processes. The identification of novel devices and optimal use of existing devices which will lead to improved clinical outcomes and more effective patient management and safety is a key feature. The manuscript management system is completely online and includes a quick and fair peer-review system. Visit http://www. dovepress.com/testimonials.php to read real quotes from authors.

Submit your manuscript here: https://www.dovepress.com/medical-devices-evidence-and-research-journal 